\title{
Quality of Life and Health State of Long - Term Unemployed in Older Production Age
}

\author{
Halina Worach-Kardas • Szymon Kostrzewski
}

Received: 22 October 2012 / Accepted: 26 April 2013 / Published online: 17 May 2013

(C) The Author(s) 2013. This article is published with open access at Springerlink.com

\begin{abstract}
The aim of the study was to evaluate the changes in the subjective quality of life (QoL) and health state of unemployed people at the age of 45 and older in the city environment. The study also aimed at evaluating some social and demographic factors on the quality of life and health of the unemployed. A group of 454 unemployed people aged 45 and older, registered in labour offices in the city of Łódź, Poland were included in the study. Two groups were formed: short-term and long-term unemployed. QoL was measured with the WHOQOL-Bref questionnaire. The main problems formulated in the study were: Does QoL and health state decrease during the period of unemployment and in what aspects? What factors can modify the changes of QoL of the unemployed? The findings of the analysis indicate that unemployment entails many negative health consequences and the long-term stress connected with being out of work leads to the decline in the quality of life and worsening of mental state. The multidimensional effects of unemployment depend not only on the economic situation of the particular household, but also on perceived health status, personal relationships and the sense of ability to work.
\end{abstract}

Keywords Health related quality of life - Health situation - Unemployment . Older production age

\section{Introduction}

Demographic data shows that growing process of population ageing will cause increased participation of people aged over 45 in the labour force. Older adults are becoming increasingly important labour market reserves. It is important to maintain a good state of health and quality of life within that group and to counteract possible

H. Worach-Kardas $(\bowtie) \cdot$ S. Kostrzewski

The Division of Public Health, the Faculty of Health Sciences, Lodz Medical University, Pl. gen. Hallera 1, 90-647 Łódź, Poland e-mail: halina_worach_kardas@onet.pl 
negative effects of prolonged professional life, including periods of unemployment and long - term unemployment, which is most health threatening.

The phenomenon of unemployment remains the focus of attention for many psychologists, economists, sociologists as well as experts in public health, as this phenomenon results in various negative effects. Work is not only a source of financial income; it plays many other roles, such as the maintenance and control of social contacts as well as serving to organize time. It develops some skills and provides certain rights. Initially, lack of work inevitably leads to worsening of the financial situation of the household and prolonged unemployment - even poverty. Financial problems, stress and loss of social identity might result in various negative social and health consequences (Jonge and Schaufeli 1998; Scanlan and Beltran 2007).

The term "quality of life" is multidimensional and depends on many factors, both subjective and objective. The quality of life (QL) reflects the level of satisfaction regarding health, material and spiritual aspects. QL comprises experiences of success and failure throughout life. It depends on individual's chosen life goals and the sense of their achievement (Glatzer 2006; McGregor et al. 2009). According to the WHO, the term is identified with the individual's position in life, in the context of the environment in which he/she lives, the system of values he/she believes in and his/her objectives, expectations, standards and fears (The WHOQOL group 1995). The quality of life has become a subject of studies of many scientific fields. The Medline database, one of the most comprehensive in the word, has gathered professional texts for more than 40 years. While in 1973, the entry "quality of life" displayed only 5 publications (Kulczycka et al. 2007), nowadays there are as many as 150,000 . Although the problem is quite common and widely discussed, not many works exist on the quality of life and the state of health of unemployed people at the age of 45 or older.

From the demographic point of view, people above the age of 45 are said to be at immobile production age. This age is associated with a specific status on the labour market. In western civilization, youth is one of the most appreciated qualities. It is associated with vitality, creativity, and willingness to work. Old age is in turn associated with many negative features such as difficulty to adapt to society and culture, inability to keep up with technological changes, and remaining far from reality. People at the age of 45, although not old yet, are somehow perceived as old. They have stopped being young (Straś-Romanowska and Frąckowiak 2008). In the opinion of some employers, such people are potentially worse employees than young people. There are huge differences in the work potential of that group in terms of psychophysical and environmental aspects. Some employees are skilled, committed to work and efficient; some others - are hardly willing to work and ineffective, mentally awaiting professional deactivation (pension, allowance). In many cases a psychological barrier deprives them of their self-esteem and prevents them from gaining new knowledge and adapting to changing conditions. People at the older production age are more susceptible to dismissal. If they lose their work, it is more difficult for them to get a new job (Urbaniak 2007).

Unemployment may cause ill health, especially poor mental state, a higher death rate, greater drug use and use of medical services than found among the employed (Claussen et al. 1993; Mathers and Schofield 1998; Przewoźniak 2000; Novo et al. 2001; Nylén et al. 2001; Hintikka et al. 2009). Studies conducted so far have not 
clearly explained the relationship between unemployment and health, and factors influencing the effects of unemployment. Research conducted over many years has led to alternative findings that indicate that the relation between unemployment and health is much more complicated than expected (e.g. the model proposed by Claussen, Bjørndal and Hjort; Graph 1). On the one hand, one body of evidence indicates that the health effects of unemployment are caused by stress and income reduction, which may lead to adverse behavior and poor health. On the other hand, there is evidence that persons with bad health, underestimated self-esteem and predisposition for depression are more vulnerable to job loss and may become unemployed by the selection process (Kalbarczyk 1999; Worach-Kardas 1996). Some research has even suggested that bad health and socio-economic factors existing for a long time before unemployment may increase the risk of job loss. Such disadvantageous factors include low parental socio - economic status, known as poverty "inheritance"; social inadequacy in school-age which is manifested in increased nervousness, depressive tendencies, fear of lack of parental acceptance; or short stature in childhood (Montgomery et al. 1996; Przewoźniak 2000). Additionally, both the nature and degree of the influence of unemployment on health may be varied. Unemployed men have a poorer state of health than unemployed women, receiving unemployment benefit or other forms of social help, as well as having a high level of education, may favourably affect health. Although marriage seems to have a positive influence on the effects of unemployment on health in women, in unemployed men it can even intensify the bad effects (Artazcoz et al. 2004; Eliason and Storrie 2009). The precise influence of unemployment on health depends on the social role and the individual perception of one's life position. A fundamental question is still open: whether unemployment leads to bad health or if simply lack of health causes unemployment. It seems that the casual relationship between state of health and unemployment is bidirectional: bad health may cause unemployment, because the employer needs a healthy and efficient worker, and any disabilities in mental or physical health may conduct to job loss. At the same time, unemployment, especially long-lasting unemployment, may contribute to the generation of new health problems and the aggravation of existing ones. Though the implications of unemployment are mostly financial, it is important to consider other associated aspects of existence, especially state of health and health- related quality of life.

\section{The Aims}

The aim of the study was to evaluate the impact of the period of unemployment on the quality of life and state of health in unemployed people at the age of 45 and older, as well as to evaluate social and demographic factors that may have influence on the quality of life and state of health of the unemployed.

The study also assessed the following aspects:

- factors conditioning the quality of life of the unemployed,

- the influence of the period of unemployment and social and economic factors on the person's self-evaluation of his/her health and chronic health disorders, 


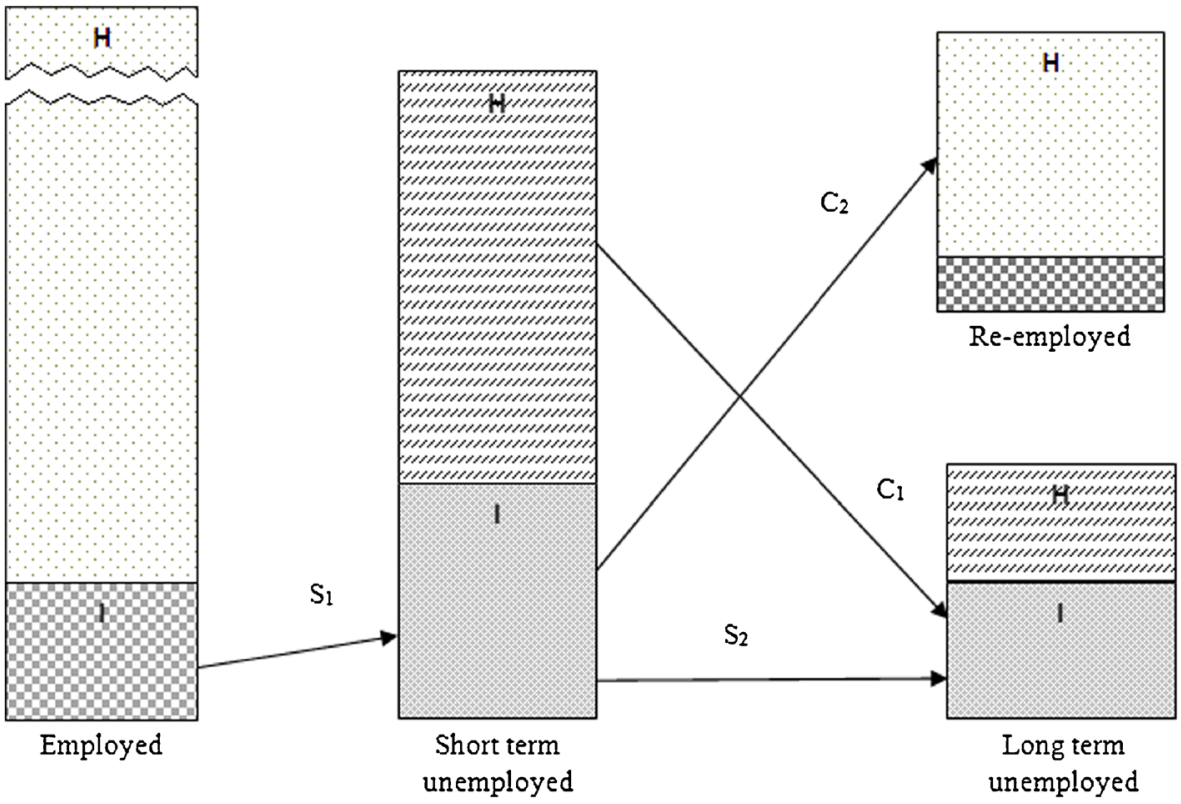

Graph 1 A model of health related selection to unemployment and of unemployment as a cause of ill health. $\mathrm{H}$ - health; I - ill; $\mathrm{S}_{1}$ - selection to job loss; $\mathrm{S}_{2}$ - selection to continuous unemployment; $\mathrm{C}_{1}-$ health unemployed become ill as a consequence of long term unemployment, $\mathrm{C}_{2}-$ sick unemployed who improve after re-employment. Source: Claussen et al. (1993). Health and re-employment in a two year follow up of long term unemployed. Journal of Epidemiology \& Community Health, 47, 15

- the general mental state of the unemployed,

- the influence of the period of unemployment and social and economic factors on the person's mental state.

\section{Materials and Methods}

The study was conducted during the years 2009 and 2010. A group of 454 unemployed people at the age of 45 and older, were included in the study. Both the main group and the reference group were recruited from unemployed persons living in the city of Łódź , a large city located in central Poland. The main group consisted of people aged 45 and older who had remained unemployed for longer than 12 months, the so- called long-term unemployed (in total $=230$ ), registered in labour offices in the city of Łódź. Every third unemployed person aged of 45 and older, registered in a labour office, was randomly studied. A group of 224 people affected by short-term unemployment (i.e. those being out of work for up to 6 months, adjusted to the main group in terms of the sex and age) was formed to allow a comparative analysis. The demographic characteristics of the examined groups, age and sex, was similar to the distribution of those of the general population - both in the city and the voivodeship.

The study was conducted with the use of a diagnostic survey and the application of a questionnaire interview technique. Three research methods were used in order to carry out the study. The authors' questionnaire addressed social and demographic 
features (marital status, education, number of children supported) as well as the period of unemployment, the financial situation of the household and the occurrence of chronic diseases in the period of unemployment. The WHOQOL-BREF questionnaire was used to evaluate the general state of health and the quality of life in general and in 4 dimensions: physical and psychological health, social relationships, and the environment of the respondent. The QL (quality of life) dimensions consists of 24 subdimensions, measuring individual approach to particular aspects of person's life. The General Health Questionnaire (GHQ - 12) was used to evaluate the physical and mental state of the studied subjects. According to the questionnaire, those who received more than 2 points were considered mentally disturbed (Makowska and Merecz 2001).

In order to evaluate the gathered data, descriptive methods and inductive statistics were used. The chi-square test for independence was applied to compare the frequencies of occurrence of the particular features in the analyzed groups. The intensity of the dependence was evaluated with the use of the Pearson correlation coefficient. When the distributions differed significantly from a normal distribution, the MannWhitney $U$ Test was used to compare the results of the two groups. To compare many groups, the Kruscal-Wallis Test was applied. The probability of error was $p<0.05$.

While conducting the study it was assumed that many demographic, social, economic and health variables will affect the evaluation of the quality of life, selfevaluation of the state of health and the mental state of the unemployed.

Hence, both single- and multi-factor logistic regression analysis was applied. The analysis made it possible to calculate the odds ratio (OR) of the occurrence of the event presented by the dichotomic variable (the evaluation of the quality of life, selfevaluation of the state of health and the occurrence of mental disturbances) depending on various independent variables. The confidence interval was $95 \%$ and the significance level $-p<0.05$.

In the single-factor logistic regression model, the authors used 22 variables analyzed with the authors' questionnaire as well as some questions taken from the WHOQOLBref questionnaire. The potential influence of demographic variables was analyzed with the following criteria: sex, age, marital status and education. An influence of social aspects was analyzed by considering the following factors: the size of the household, the presence of children or unemployed members of the household, satisfaction with personal relationships and support. The economic variable reflected self-evaluation of the economic state of the household. The authors evaluated also the influence of variables referring to activity and professional activation, multiple registration in a labour office, satisfaction with ability to work, attempts to find paid employment, the type of work: permanent, temporary, participation in courses and professional training. An influence of variables referring to health and health care was analyzed with the following factors: self-evaluation of health, experiencing negative feelings (sadness, depression, melancholy), diagnosis or exacerbation of chronic diseases in the period of unemployment, satisfaction with access to health care. Certain behaviours and lifestyle, such as being a smoker or non-smoker and doing regular physical exercise, also contributed to self-rated health. The application of the single-factor analysis allowed the elimination all variables which were statistically insignificant. The multi-factor logistic regression analysis facilitated an analysis of how much the variables contribute to an overall positive quality of life, a negative self-evaluation of health and mental disturbances. The STATISTICA 8 package was used for statistical purposes. 


\section{Results}

The Description of the Group who Took Part the Experiment

Two hundred and thirty long-term unemployed subjects (the main group) and 224 short-term unemployed subjects (the comparative group) were included in the study. Having applied the research methodology, the groups were made homogenous in terms of sex and age. In both groups, the proportions of women and men were similar: $50.4 \%$ vs. $49.6 \%$. The average age of long-term unemployed subjects was $52 ., 7 \pm 4 ., 7$ years and short-term unemployed $51.8 \pm 5.1$ years. (Table 1).

The Perceived Quality of Life in the Studied Persons

The results confirm the presence of a statistically significant, but not particularly strong, relationship between the period of unemployment and global satisfaction with the quality of life $(p<0.001 ; C=0.20)$. The percentage of positive opinions was significantly lower in the group of the long-term unemployed subjects than in the group of the short-term unemployed subjects $(23.5 \%$ vs. $42.4 \%)$. Moreover, it was more common for the subjects from

Table 1 Social and demographic characteristic of the studied groups

\begin{tabular}{|c|c|c|c|c|}
\hline \multirow[t]{3}{*}{ Characteristic } & \multicolumn{4}{|l|}{ Group } \\
\hline & \multicolumn{2}{|c|}{ Long-term unemployed } & \multicolumn{2}{|c|}{ Short-term unemployed } \\
\hline & $N=230$ & $\%$ & $N=224$ & $\%$ \\
\hline \multicolumn{5}{|l|}{ Sex: } \\
\hline Men & 114 & 49.6 & 111 & 49.6 \\
\hline Women & 116 & 50.4 & 113 & 50.4 \\
\hline Age [in years] & $52,7 \pm 4,7$ & & $51,8 \pm 5,1$ & \\
\hline \multicolumn{5}{|l|}{ Marital status: } \\
\hline Single & 27 & 11.7 & 19 & 8.5 \\
\hline Married & 117 & 50.9 & 150 & 66.9 \\
\hline Cohabitation & 9 & 3.9 & 8 & 3.6 \\
\hline Divorced/Separated & 38 & 16.5 & 36 & 16.1 \\
\hline Widow/Widower & 39 & 17.0 & 11 & 4.9 \\
\hline \multicolumn{5}{|l|}{ Education: } \\
\hline Elementary & 55 & 23.9 & 26 & 11.6 \\
\hline Vocational & 90 & 39.1 & 75 & 33.5 \\
\hline Secondary comprehensive & 35 & 15.2 & 39 & 17.4 \\
\hline Secondary vocational & 36 & 15.7 & 55 & 24.6 \\
\hline University undergraduate and/or post-secondary & 4 & 1.7 & 11 & 4.9 \\
\hline University & 10 & 4.4 & 18 & 8.0 \\
\hline
\end{tabular}


the main group to be unable to state explicitly whether the quality of their life is either positive or negative compared with those from the comparative group (44\% vs. $33.9 \%$ ). More than one third of the long-term unemployed subjects considered the quality of their life negative, whereas in the comparative group, the percentage of negative opinions was smaller and made up only one fourth of the studied subjects. (Table 2).

The quality of life of the unemployed was analyzed in four dimensions: physical health, mental health, social relationships and the environment (Table 3). The analysis showed that long-term unemployed people consider the quality of their life worse in all the four dimensions. The greatest difference between the studied groups was in the environment $(-0.84)$, followed by physical health and social relationships $(-0.81$ each) and finally, the smallest - in mental health $(-0.69)$.

While analyzing the quality of life in according to the 24 sub-dimensions of the quality of life given in the WHOQOL-BREF questionnaire, the authors identified 14 aspects in which there are significant differences between the studied groups (Table 4). It was concluded that long - term unemployed persons more often:

- feel they are unable to do any work (paid or unpaid),

- feel they are no longer able to lead a regular, everyday life,

- feel that physical pain limits their life activity,

- feel their life is useless and unimportant,

- stop accepting their physical appearance,

- does not feel happy with life,

- such negative feelings like sadness, apathy and fear become stronger,

- are less satisfied with their sexual life,

- are less satisfied with housing conditions and the environment,

- are less satisfied with their financial situation,

- are less able to move (transport),

- have less access to information needed in everyday life.

Table 2 The quality of life and the period of unemployment

\begin{tabular}{|c|c|c|c|c|c|c|}
\hline \multirow[t]{2}{*}{ How much are you satisfied with the quality of your life? } & \multicolumn{2}{|c|}{$\begin{array}{l}\text { Long-term } \\
\text { unemployed }\end{array}$} & \multicolumn{2}{|c|}{$\begin{array}{l}\text { Short-term } \\
\text { unemployed }\end{array}$} & \multicolumn{2}{|c|}{ Total } \\
\hline & $n$ & $\%$ & $n$ & $\%$ & $N$ & $\%$ \\
\hline Highly dissatisfied & 10 & 4.4 & 4 & 1.8 & 14 & 3.1 \\
\hline Dissatisfied & 64 & 27.7 & 49 & 21.9 & 113 & 24.9 \\
\hline Neither satisfied nor dissatisfied & 102 & 44.4 & 76 & 33.9 & 178 & 39.1 \\
\hline Satisfied & 51 & 22.2 & 90 & 40.2 & 141 & 31.1 \\
\hline Highly satisfied & 3 & 1.3 & 5 & 2.2 & 8 & 1.8 \\
\hline Total & 230 & 100.0 & 224 & 100.0 & 454 & 100.0 \\
\hline
\end{tabular}

chi2 $=19.572 ; p<0.001 ; C=0.20$ 
Table 3 Dimensions of the quality of life and the period of unemployment

\begin{tabular}{lcl}
\hline $\begin{array}{l}\text { Calculated } \\
\text { parameters }\end{array}$ & $\begin{array}{l}\text { Long-term } \\
\text { unemployed }\end{array}$ & $\begin{array}{l}\text { Short-term } \\
\text { unemployed }\end{array}$ \\
\hline Physical health & & \\
MEDIAN & 14.46 & 15.27 \\
Me & 14.29 & 15.14 \\
SD & 2.12 & 2.39 \\
Comparison & $z=3.799 ; p<0.001$ & \\
Mental health & & \\
MEDIAN & 12.46 & 13.15 \\
Me & 12.00 & 13.00 \\
SD & 2.39 & 2.49 \\
Comparison & $z=3.580 ; p<0.001$ & \\
Social aspect & & \\
MEDIAN & 13.51 & 14.32 \\
Me & 14.00 & 2.37 \\
SD & 2.41 & \\
Comparison & $z=3.340 ; p<0.001$ & \\
Environmental aspect & \\
MEDIAN & 11.54 & 12.38 \\
Me & 11.50 & 2.03 \\
SD & 1.78 & \\
Comparison & $z=4.654 ; p<0.001$ & \\
\hline & & \\
& &
\end{tabular}

The authors did not observe any differences between the studied groups (Table 5) regarding the remaining 10 sub-dimensions of the quality of life in the WHOQOLBREF questionnaire. In other words, no relationship was observed between the period of unemployment and:

- level of vitality,

- mobility,

- satisfaction with sleep,

- possibility of leading a regular, everyday life which depends on treatment,

- ability to concentrate,

- self-evaluation,

- satisfaction with provided social support,

- feeling of physical and mental security,

- possibility of involving in leisure,

- satisfaction with access to medical care.

The multi-factor logistic regression analysis showed that four factors mostly contribute to a positive evaluation of the quality of life. The financial situation of the household was found to be the most important factor. If it was average, the probability of making a positive evaluation of the quality of life grew by 4.5 times 
Table 4 Sub-dimensions of the quality of life in the WHOQOL-BREF questionnaire with statistically significant differences between the long-term unemployed and short-term unemployed

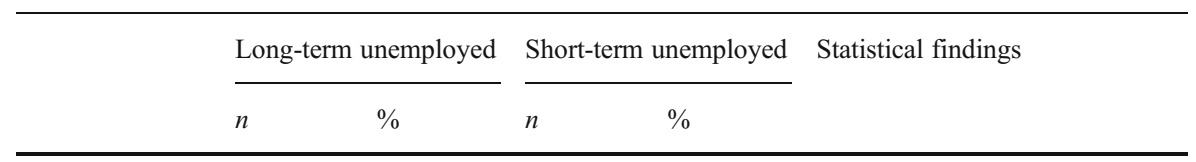

Satisfaction with ability to work

chi2=16,306; $p<0,001 ; C=0,186$

$\begin{array}{llrrr}\text { No } & 33 & 14,4 & 26 & 11,6 \\ \text { Medium } & 98 & 42,6 & 61 & 27,2 \\ \text { Yes } & 99 & 43,1 & 137 & 61,2\end{array}$

Satisfaction with the ability to lead a regular, everyday life

chi2 $=12,679 ; p<0,01 ; C=0,165$

$\begin{array}{lrrrr}\text { No } & 37 & 16,1 & 22 & 9,8 \\ \text { Medium } & 119 & 51,7 & 95 & 42,4 \\ \text { Yes } & 74 & 32,2 & 107 & 47,8\end{array}$

Feeling that physical pain limits life

$\begin{array}{lrrrr}\text { No } & 76 & 33 & 110 & 49,1 \\ \text { Medium } & 105 & 45,7 & 80 & 35,7 \\ \text { Yes } & 49 & 21,3 & 34 & 15,2\end{array}$

chi2 $=12,599 ; p<0,01 ; C=0,164$

Feeling of sense and importance of own life

chi2=21,369; $p<0,001 ; C=0,212$

$\begin{array}{lrrrr}\text { No } & 9 & 3,9 & 8 & 3,6 \\ \text { Medium } & 116 & 50,4 & 80 & 35,7 \\ \text { Yes } & 105 & 45,7 & 136 & 60,7\end{array}$

Acceptance of your own appearance

chi2 $=7,344 ; p<0,05 ; C=0,134$

$\begin{array}{lrrrr}\text { No } & 2 & 0,9 & 5 & 2,2 \\ \text { Medium } & 121 & 52,6 & 90 & 40,2 \\ \text { Yes } & 107 & 46,5 & 129 & 57,6\end{array}$

Feeling happy with life

$\begin{array}{lrrrr}\text { No } & 14 & 6,1 & 11 & 4,9 \\ \text { Medium } & 117 & 50,9 & 74 & 33 \\ \text { Yes } & 99 & 43 & 139 & 62\end{array}$

chi2=18,385; $p<0,001 ; C=0,197$

Frequency of negative feelings: misery, fear, apathy

chi2 $=9,149 ; p<0,05 ; C=0,141$

$\begin{array}{lrrrr}\text { Never } & 29 & 12,6 & 41 & 18,3 \\ \text { Seldom } & 86 & 37,4 & 101 & 45,1 \\ \text { Often or always } & 115 & 50 & 82 & 36,6\end{array}$

Satisfaction with personal relationships

chi2=14,436; $p<0,01 ; C=0,176$

$\begin{array}{lrrrr}\text { No } & 18 & 7,8 & 21 & 9,4 \\ \text { Medium } & 82 & 35,7 & 47 & 21 \\ \text { Yes } & 130 & 56,5 & 156 & 69,7\end{array}$

Satisfaction with sexual life

chi2=11,617; $p<0,05 ; C=0,158$

$\begin{array}{lrrrr}\text { No } & 32 & 13,9 & 22 & 9,8 \\ \text { Medium } & 120 & 52,2 & 91 & 40,6 \\ \text { Yes } & 78 & 33,9 & 111 & 49,5\end{array}$

Feeling of healthy environment

chi2 $=22,366 ; p<0,001 ; C=0,23$

$\begin{array}{lrrrr}\text { No } & 25 & 10,9 & 6 & 2,7 \\ \text { Medium } & 166 & 72,2 & 142 & 63,4\end{array}$


Table 4 (continued)

\begin{tabular}{|c|c|c|c|c|c|}
\hline & \multicolumn{2}{|c|}{ Long-term unemployed } & \multicolumn{2}{|c|}{ Short-term unemployed } & \multirow[t]{2}{*}{ Statistical findings } \\
\hline & $n$ & $\%$ & $n$ & $\%$ & \\
\hline Yes & 39 & 17 & 76 & 33,9 & \\
\hline \multicolumn{5}{|c|}{ Satisfaction with housing conditions } & chi $2=15,394 ; p<0,01 ; C=0,181$ \\
\hline No & 32 & 13,9 & 18 & 8 & \\
\hline Medium & 78 & 33,9 & 58 & 25,9 & \\
\hline Yes & 120 & 52,2 & 148 & 66,1 & \\
\hline \multicolumn{5}{|c|}{ Possessing financial resources to satisfy needs } & chi $2=12,865 ; p<0,01 ; C=0,166$ \\
\hline No & 104 & 45,2 & 65 & 29,0 & \\
\hline Medium & 116 & 50,4 & 145 & 64,7 & \\
\hline Yes & 10 & 4,3 & 14 & 6,3 & \\
\hline \multicolumn{5}{|c|}{ Satisfaction with the ability to move (transport) } & $\operatorname{chi} 2=12,555 ; p<0,01 ; C=0,164$ \\
\hline No & 25 & 10,9 & 25 & 11,1 & \\
\hline Medium & 95 & 41,3 & 71 & 31,7 & \\
\hline Yes & 110 & 47,8 & 128 & 57,2 & \\
\hline \multicolumn{5}{|c|}{ Access to information needed in everyday life } & chi2 $=28,942 ; p<0,001 ; C=0,245$ \\
\hline No & 0 & 0 & 2 & 0,9 & \\
\hline Medium & 175 & 76,1 & 115 & 51,4 & \\
\hline Yes & 55 & 23,9 & 107 & 47,7 & \\
\hline
\end{tabular}

$(\mathrm{OR}=4.511)$. The quality grew more than five times if the financial situation was very good $(\mathrm{OR}=5.081)$. Satisfaction with health resulted in a double increase in a positive evaluation of the quality of life $(\mathrm{OR}=2.331)$. If the satisfaction was extremely high, the evaluation grew by almost four times $(\mathrm{OR}=3.990)$. The social factor, i. e. satisfaction with personal relationships raised the evaluation 2.5 times $(\mathrm{OR}=2.620)$. If there were no more unemployed people in the household, the evaluation grew by more than two times $(\mathrm{OR}=2.296)($ Graph 2).

The Health State of the Studied Subjects

The authors did not note a statistically significant difference between the long-term and short-term unemployed subjects with regard to satisfaction with their state of health $(p>0.05)$. Almost half the studied subjects $(45 \%)$ were satisfied with their health, whereas in the comparative group the satisfied subjects made up $55 \%$. Those who were long-term unemployed also slightly more often expressed their dissatisfaction with their state of health (21.3\% vs. $17.4 \%)$ (Table 6).

In the multi-factor logistic regression analysis, the most important feature remains the sense of dissatisfaction with ability to work. In the study it appeared to have a negative impact and resulted in a negative self-evaluation $(\mathrm{OR}=5.043)$. Physical inactivity and dissatisfaction with personal relationships were another significant factors contributing to increase negative self-evaluation of the state of health: 2.7 and 2.5 times, corresponding to $\mathrm{OR}=2.777$ and $\mathrm{OR}=2.517$ (Graph 3). 
Table 5 Sub-dimensions of the quality of life in the WHOQOL-BREF questionnaire where there are no statistically significant differences between the long- and short-term unemployed.

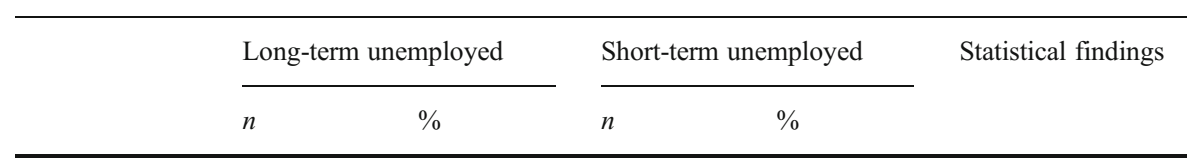

Feeling "energy" to lead a regular life

$\begin{array}{lrrrr}\text { No } & 6 & 2,6 & 6 & 2,7 \\ \text { Medium } & 135 & 58,7 & 105 & 46,9 \\ \text { Yes } & 89 & 38,7 & 113 & 50,4\end{array}$

Ability to be mobile

chi2=9,098; $p>0,05$

$\begin{array}{lrrrr}\text { Poor } & 7 & 3 & 4 & 1,8 \\ \text { Medium } & 32 & 13,9 & 21 & 9,4 \\ \text { Good } & 191 & 83,1 & 199 & 88,8\end{array}$

Satisfaction with sleep

$\begin{array}{lrrrr}\text { No } & 55 & 23,9 & 46 & 20,6 \\ \text { Medium } & 68 & 29,6 & 49 & 21,9 \\ \text { Yes } & 107 & 46,5 & 129 & 57,5\end{array}$

Possibility of leading regular, everyday life which depends on treatment

$\begin{array}{llrrr}\text { No } & 90 & 39,1 & 112 & 50 \\ \text { Medium } & 85 & 37 & 67 & 29,9 \\ \text { Yes } & 55 & 23,9 & 45 & 20,1\end{array}$

Ability to concentrate easily

chi2 $=7,044 ; p>0,05$

$\begin{array}{lrrrr}\text { No } & 7 & 3 & 3 & 1 \\ \text { Medium } & 62 & 27 & 53 & 24 \\ \text { Yes } & 161 & 70 & 168 & 75\end{array}$

Feeling of self-satisfaction

$\begin{array}{lrrrr}\text { No } & 21 & 9,2 & 15 & 6,7 \\ \text { Medium } & 67 & 29,1 & 60 & 26,8 \\ \text { Yes } & 142 & 61,7 & 149 & 66,5\end{array}$

Feeling of satisfaction with the friends' support

chi2=6,095; $p>0,05$

$\begin{array}{lrrrr}\text { No } & 42 & 18,3 & 25 & 11,2 \\ \text { Medium } & 56 & 24,3 & 57 & 25,4 \\ \text { Yes } & 132 & 57,4 & 142 & 63,4\end{array}$

Feeling of security in everyday life (physical and mental)

chi2 $=6,981 ; p>0,05$

$\begin{array}{lrrrr}\text { No } & 19 & 8,3 & 14 & 6,3 \\ \text { Medium } & 169 & 73,4 & 155 & 69,2 \\ \text { Yes } & 42 & 18,3 & 55 & 24,6\end{array}$

Possibility of spending free time according to personal preferences

$\begin{array}{lrrrr}\text { No } & 17 & 7,4 & 12 & 5,4 \\ \text { Medium } & 166 & 72,1 & 156 & 69,6 \\ \text { Yes } & 47 & 20,5 & 56 & 25\end{array}$

Satisfaction with access to medical care

chi2 $=4,508 ; p>0,05$

$\begin{array}{lllll}\text { No } & 65 & 28,3 & 53 & 23,7 \\ \text { Medium } & 78 & 33,9 & 93 & 41,5 \\ \text { Yes } & 87 & 37,8 & 78 & 34,8\end{array}$


For the purpose of the analysis of the impact of long-term unemployment on the mental state, the General Health Questionnaire (GHQ - 12) was used. Out of the whole group of the studied subjects, as many as $48 \%$ demonstrated a risk of developing mental disorders. A statistically significant dependence between the period of unemployment and the result of the GHQ - 12 survey $(p<0.01)$ was observed. GHQ - 12 results higher than 2 points, indicating worsened mental state and a risk of developing symptoms such as depression or anxiety, were significantly more common in the group of long-term unemployed subjects $(55.2 \%$ whereas $41.1 \%$ in short-term unemployed subjects) (Table 7).

Dissatisfaction with the ability to work turned out to be a factor seriously contributing to a negative self-evaluation. The risk of expressing such a view grew by more than ten times $(\mathrm{OR}=10.752)$. Inability to assess the state of health resulted in a five times higher risk of expressing a negative self-evaluation $(\mathrm{OR}=5.698)$ and in the event of dissatisfaction with personal relationships, the risk of developing mental disorders was more than four times higher $(\mathrm{OR}=4.236)$ (Graph 4).

The nature of chronic diseases was also analyzed. More than half of the long-term unemployed subjects (52.2\%) admitted that they had been diagnosed with a chronic disease during their period of unemployment, or if the disease had already existed, it was exacerbated during that period. In the comparative group the percentage was $45 \%$. Disorders of the cardiovascular system were the most common in both groups. The incidence of disease in the study and comparative groups was not significantly different $(p>0.05)$ with the exception of diseases of the respiratory system, which were significantly more common in long-term unemployed people $(p<0.01)-7.8 \%$ and $1.8 \%$ (Table 8 ). Generally women complained about chronic disorders more often than men. Only diseases of the respiratory system in the study group and diseases of the cardiovascular system in the comparative group were more often noted in men. No statistically significant relationship was observed between the incidence of chronic disease and sex - both in the main and the reference group. However it was indicated that women more often suffered from mental disorders than men - the difference was statistically significant $(p>0,05)$ (Tables 9 and 10).

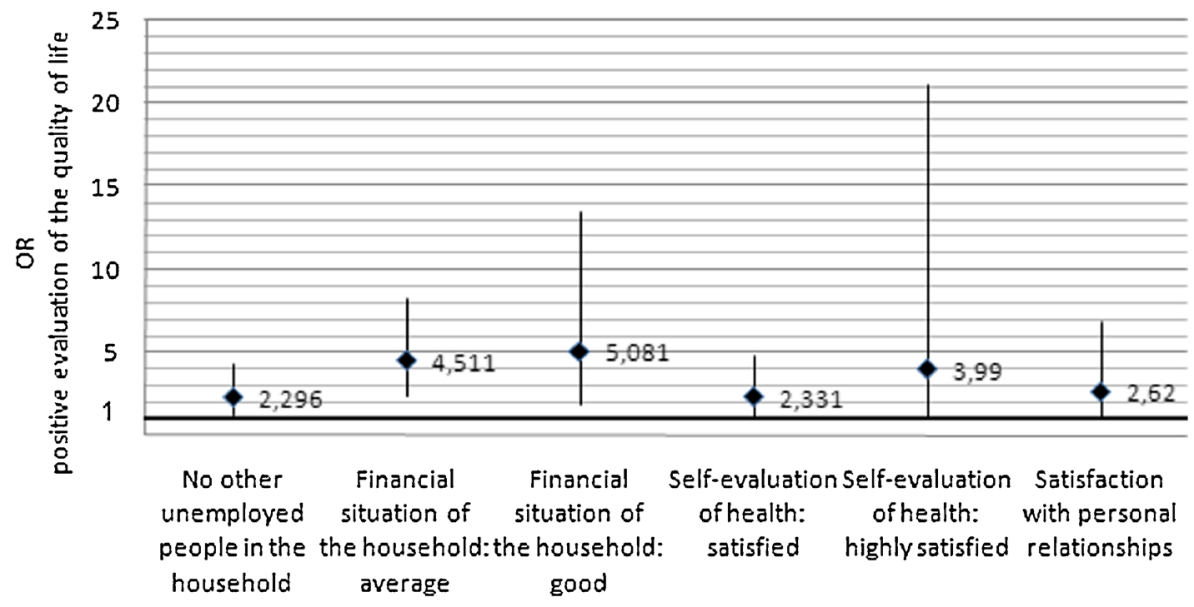

Graph 2 Odds ratio - Chance for a positive evaluation of the quality of life with $95 \%$ confidence interval 
Table 6 Self-evaluation of health and the period of unemployment

\begin{tabular}{|c|c|c|c|c|c|c|}
\hline \multirow[t]{2}{*}{ How much are you satisfied with your health? } & \multicolumn{2}{|c|}{$\begin{array}{l}\text { Long-term } \\
\text { unemployed }\end{array}$} & \multicolumn{2}{|c|}{$\begin{array}{l}\text { Short-term } \\
\text { unemployed }\end{array}$} & \multicolumn{2}{|c|}{ Total } \\
\hline & $n$ & $\%$ & $n$ & $\%$ & $N$ & $\%$ \\
\hline Highly dissatisfied & 6 & 2.6 & 3 & 1.3 & 9 & 2.0 \\
\hline Dissatisfied & 43 & 18.7 & 36 & 16.1 & 79 & 17.4 \\
\hline Neither satisfied nor dissatisfied & 77 & 33.5 & 62 & 27.7 & 139 & 30.6 \\
\hline Satisfied & 97 & 42.2 & 112 & 50.0 & 209 & 46.0 \\
\hline Highly satisfied & 7 & 3.0 & 11 & 4.9 & 18 & 4.0 \\
\hline Total & 230 & 100.0 & 224 & 100.0 & 454 & 100.0 \\
\hline
\end{tabular}

chi2 $=5.126 ; p>0.05$

\section{Discussion}

The period of unemployment seems to influence the sense of well - being of unemployed people. In the group of long - term unemployed, $23.5 \%$ of subjects considered the quality of life positive while in the reference group, $42.2 \%$. That evaluation is worse than the evaluation made by the young unemployed (aged 20 25) where $67 \%$ subjects considered their quality of life positive (Axelsson et al. 2007). However, studies conducted on a representative group of Polish inhabitants show that quality of life of the unemployed subjects presented in this study is much worse: the evaluation of positive quality of life for Poland is around $70 \%$ (Wciórka 2007; Czapiński and Panek 2009). Some other studies also indicate that the employed consider the quality of their life better than those who are unemployed (Martella and Maass 2000; Bernklev et al. 2006; Jiang and Hesser 2006; Zagożdżon and Ejsmond

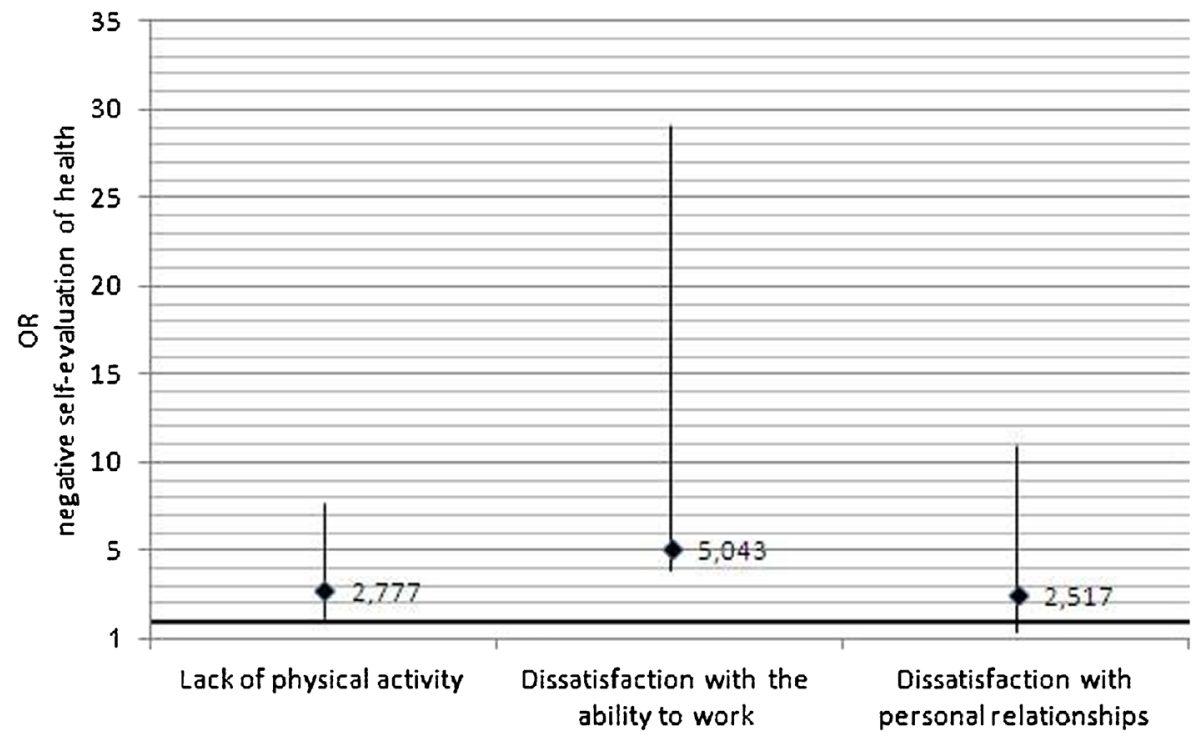

Graph 3 Odds ratio - risk of a negative self-evaluation of health with $95 \%$ confidence interval 
Table 7 General mental state and the period of unemployment

\begin{tabular}{|c|c|c|c|c|c|c|}
\hline \multirow[t]{2}{*}{ GHQ 12 Questionnaire results } & \multicolumn{2}{|c|}{ Long-term unemployed } & \multicolumn{2}{|c|}{ Short-term unemployed } & \multicolumn{2}{|c|}{ Total } \\
\hline & $n$ & $\%$ & $n$ & $\%$ & $N$ & $\%$ \\
\hline GHQ $12 \leq 2$ & 103 & 44.8 & 132 & 58.9 & 235 & 51.8 \\
\hline GHQ $12>2$ & 127 & 55.2 & 92 & 41.1 & 219 & 48.2 \\
\hline Total & 230 & 100.0 & 224 & 100.0 & 454 & 100.0 \\
\hline
\end{tabular}

chi2 $=9.095 ; p<0.01 ; C=0.140$

2008; Vanassche et al. 2012). One of the most important factors influencing the general evaluation of the quality of life was the financial situation of the household. A good financial situation significantly increased the chance of positive opinion of quality of life of the unemployed. This confirms the findings from previous studies in which financial condition, especially low - income, is a significant factor of low quality of life (Zahran et al. 2003; Powdthavee 2010; Rojas 2011). However, financial state is not the only factor which defines quality of life, social relationships also play a vital role in the level of quality of life of the unemployed. Satisfaction with personal relationships and living in a household with no other persons without a job may lead to a good perception of quality of life: this confirms the results of other studies that emphasize the role of social environment and the variety and extent of social relations in modifying the health effects of unemployed (Leeflang et al. 1992; Béland et al. 2002).

Unemployment-related stress results in lower self-evaluation of the state of health. The results are similar to the previous studies (Blaxter 1990; Latalski et al. 2004; Kostrzewski and Worach-Kardas 2008). In comparison to the whole population, the long-term unemployed subjects consider their state of health more negative. Only $45 \%$ of long-term unemployed subjects claim it to be good, but the average

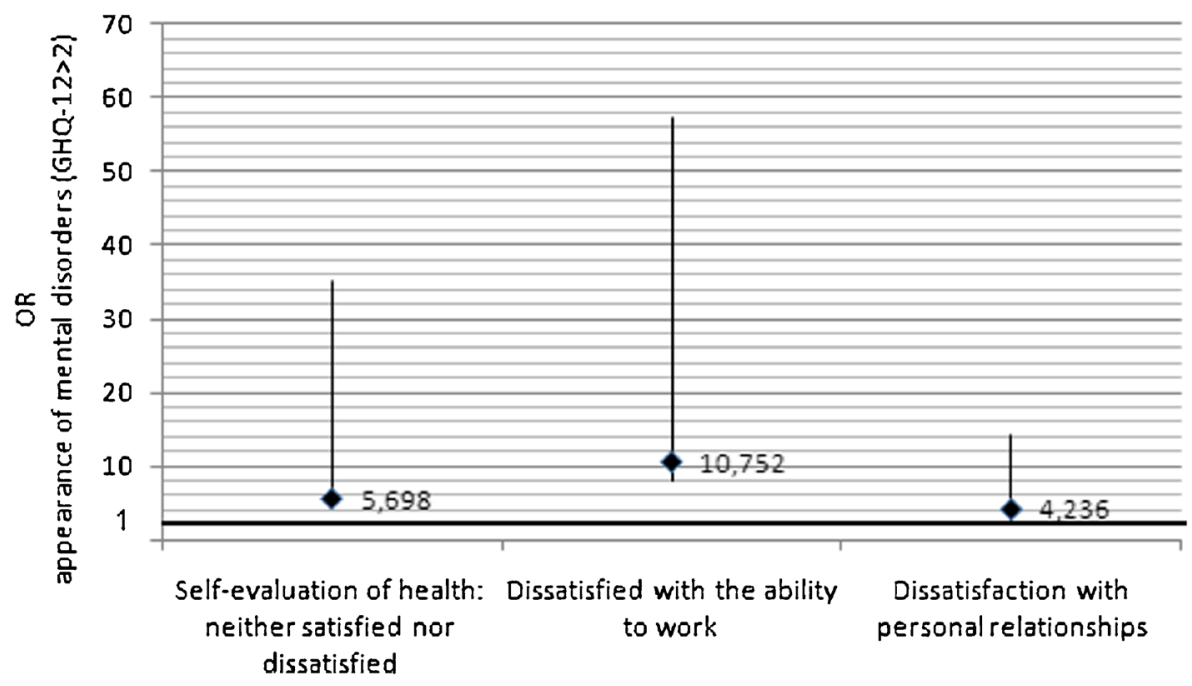

Graph 4 Odds ratio - risk of appearance of mental disorders (GHQ-12>2) with $95 \%$ confidence interval 
Table 8 Chronic diseases and the period of unemployment

\begin{tabular}{|c|c|c|c|c|c|c|}
\hline \multirow[t]{2}{*}{ Disease } & \multicolumn{2}{|c|}{$\begin{array}{l}\text { Long-term } \\
\text { unemployed }\end{array}$} & \multicolumn{2}{|c|}{$\begin{array}{l}\text { Short-term } \\
\text { unemployed }\end{array}$} & \multicolumn{2}{|c|}{$\begin{array}{l}\text { Comparison } \\
\text { of the incidence }\end{array}$} \\
\hline & $n$ & $\%$ & $n$ & $\%$ & Chi2 & $p$ \\
\hline Cardiovascular diseases & 73 & 31.7 & 55 & 24.6 & 2.894 & $p>0.05$ \\
\hline Diseases of the alimentary tract & 23 & 10.0 & 12 & 5.4 & 3.438 & $p>0.05$ \\
\hline Diseases of the respiratory system & 18 & 7.8 & 4 & 1.8 & 8.980 & $p<0,01$ \\
\hline Mental disorders (including neuroses) & 17 & 7.4 & 23 & 10.3 & 1.169 & $p>0.05$ \\
\hline Other chronic diseases & 42 & 18.3 & 45 & 20.1 & 0.347 & $p>0.05$ \\
\hline $\begin{array}{l}\text { No disorders or no exacerbation of existing } \\
\text { disorders observed }\end{array}$ & 110 & 47.8 & 123 & 54.9 & 2.280 & $p>0.05$ \\
\hline
\end{tabular}

The percentage is not 100 as the subjects could choose more than one option

percentage for the whole Polish population is $72 \%$ (Czapiński and Panek 2009). One clear indication of the findings is that unemployment-related stress results in a worsened mental state and the appearance of negative emotions (Leeflang et al. 1992; Claussen et al. 1993; Bjarnason and Sigurdardottir 2003). The authors concluded that long-term unemployment is highly stressful and in the group of the subjects remaining without work for more than 12 months, apathy and depression symptoms appeared. Those remaining out of work for a period up to 6 months more often developed mental disorders. In the opinion of some researchers, some serious psychological disorders might sometimes appear within the period of 6 months following the loss of work. Although this psychic instability wears off after the this 6-month period, they are still threatened with anxiety, fears, lack of self-confidence and depression (Rowley and Feather 1987; Warr 2004).

Population studies, both retrospective and prospective, indicate that in the period of unemployment, the probability of developing somatic diseases is higher. The longer the

Table 9 Incidence of chronic diseases according to sex in the group of the long-term unemployed

\begin{tabular}{|c|c|c|c|c|c|c|}
\hline \multirow[t]{3}{*}{ Disease } & \multicolumn{4}{|c|}{$\begin{array}{l}\text { Long-term } \\
\text { unemployed }\end{array}$} & \multicolumn{2}{|c|}{$\begin{array}{l}\text { Comparison of } \\
\text { the incidence }\end{array}$} \\
\hline & \multicolumn{2}{|c|}{ Men } & \multicolumn{2}{|c|}{ Women } & & \\
\hline & $n$ & $\%$ & $n$ & $\%$ & Chi2 & $p$ \\
\hline Cardiovascular diseases & 33 & 28.9 & 40 & 34.5 & 0.813 & $p>0.05$ \\
\hline Diseases of the alimentary tract & 10 & 8.8 & 13 & 11.2 & 0.379 & $p>0.05$ \\
\hline Diseases of the respiratory system & 11 & 9.6 & 7 & 6.0 & 1.041 & $p>0.05$ \\
\hline Mental disorders (including neuroses) & 4 & 3.5 & 13 & 11.2 & 4.978 & $p<0.05$ \\
\hline Other chronic diseases & 18 & 15.8 & 24 & 20.7 & 0.925 & $p>0.05$ \\
\hline No disorders or no exacerbation of existing disorders observed & 59 & 51.8 & 51 & 44 & 1.398 & $p>0.05$ \\
\hline
\end{tabular}

The percentage is not 100 as the subjects could choose more than one option 
Table 10 Incidence of chronic diseases according to sex in the group of the short-term unemployed

\begin{tabular}{|c|c|c|c|c|c|c|}
\hline \multirow[t]{3}{*}{ Disease } & \multicolumn{4}{|c|}{ Short-term unemployed } & \multirow{2}{*}{\multicolumn{2}{|c|}{$\begin{array}{l}\text { Comparison of } \\
\text { the incidence }\end{array}$}} \\
\hline & \multicolumn{2}{|c|}{ Men } & \multicolumn{2}{|c|}{ Women } & & \\
\hline & $n$ & $\%$ & $n$ & $\%$ & Chi2 & $p$ \\
\hline Cardiovascular diseases & 30 & 27.0 & 25 & 22.1 & 0.726 & $p>0.05$ \\
\hline Diseases of the alimentary tract & 6 & 5.4 & 6 & 5.3 & 0.201 & $p>0.05$ \\
\hline Diseases of the respiratory system & 1 & 0.9 & 3 & 2.7 & 0.237 & $p>0.05$ \\
\hline Mental disorders (including neuroses) & 6 & 5.4 & 17 & 15.0 & 5.647 & $p<0.05$ \\
\hline Other chronic diseases & 17 & 15.3 & 28 & 24.8 & 3.124 & $p>0.05$ \\
\hline No disorders or no exacerbation of existing disorders observed & 64 & 57.7 & 59 & 52.2 & 0.671 & $p>0.05$ \\
\hline
\end{tabular}

The percentage is not 100 as the subjects could choose more than one option

period, the more episodes of somatic disease are noted (Martikainen and Valkonen 1996; Leeflang et al. 1992). This study only partly confirms these observations. Long-term unemployed subjects admitted suffering from chronic diseases more often than shortterm subjects did. The difference was not statistically significant. According to previous studies, unemployed people more often develop and die of cardiovascular diseases (Geyer and Peter 2003; Eliason and Storrie 2009). The present study shares the same observation : the most common diseases or were most often exacerbated in the period of unemployment were cardiovascular diseases. However, the study confirms that diseases of the respiratory system are related to length of unemployment. The results of studies conducted on the Finnish labour market and studies by L. Fagin, S.V. Kasl turned out to be similar (Przewoźniak 2000; Linkola 2007; Bańka 1992).

\section{Conclusions}

Unemployment induces stress and can be treated as a negative environmental factor. According to the scale created by American psychologists T.H. Holmes and R. Rahe showing the relationship between life events and stress, loss of work is placed in the top ten most stressful life events. Unemployment is only less stressful than a disease or any other injury or the death of a relative. It is more stressful than a relative's deterioration of health, retirement or sexual problems (Holmes and Rahe 1967).

Results of the loss of work are not the same for all unemployed people. They depend on the age of the person and their time on the labour market. For people at medium- and late-productivity age, unemployment might often mean the end of their professional career, decreased pension benefits and further health disorders, which grow in number with age.

Multi-factor logistic regression analysis confirmed that the effect of unemployment depends not only on the economic situation of the household but also on other accompanying factors. In order to maintain a good sense of well-being, it is important that unemployed, as well as unemployed care institutions, should be aware that factors other than noneconomic ones are also significant. It is important to take action 
aimed at maintaining both a good state of health and the individual's sense of good health through physical activity and a healthy diet. Also efforts to counteract social exclusion, maintain diverse social relationships and promote integration and participation in the community may have an important positive influence on the sense of well-being of the unemployed.

Although differences in health self-evaluation between long-term and shortterm unemployed were observed, these were not statistically significant. The casual relationships between health and unemployment seem to be sufficiently unclear to make a clear identification of the deterioration of the state of health during prolonged unemployment impossible. Long- term unemployment seems to have more influence on subjective quality of life, in all dimensions, and health self-evaluation was an important factor increasing the chance of positive evaluation of quality of life. A multi - analysis conducted by Veenhoven (2008) shows that happiness can foster physical health and protect from ill health. Happiness and a sense of well - being of the unemployed should be seen not only as an outcome of their life situation, but as prediction of their health potential, which is essential for re - employment. The research outcomes show that further studies on the relationship between health and unemployment should consider the modifying role of various socio - economic factors on the effects of unemployment, not only from the perspective of the physical health of the unemployed, but also that of quality of life and their subjective sense of well - being.

Acknowledgments A grant to conduct the study was given by the President of Łódź - Regulation no 2957/V/09 as of 30 March 2009; Topic 1:"Biological, cultural and social aspects of environmental stress and its influence on the life of Łódź inhabitants" - project Ed-VII-4346/G-1,4,9/09 and by the European Social Fund (the Integrated Regional Operational Programme 2.6 - The grant: "Grants supporting innovative scientific research carried out by doctoral students").

Open Access This article is distributed under the terms of the Creative Commons Attribution License which permits any use, distribution, and reproduction in any medium, provided the original author(s) and the source are credited.

\section{References}

Artazcoz, L., Benach, J., Borrell, C., \& Cortès, I. (2004). Unemployment and mental health: understanding the interactions among gender, family roles, and social class. American Journal of Public Health, 94(1), 82-88.

Axelsson, L., Andersson, I. H., Edén, L., \& Ejlertsson, G. (2007). Inequalities of quality of life in unemployed young adults: a population - based questionnaire study. International Journal for Equity in Health, 6, 1-9.

Bańka, A. (1992). How to define unemployment from the psychological perspective? In A. Bańka (Ed.), Manual of psychological help (pp. 22-30). Poznań: PRINT Publishing House - B.

Béland, F., Birch, S., \& Stoddart, G. (2002). Unemployment and health: contextual - level influences on the production of health in populations. Social Science \& Medicine, 55(11), 2033-2052.

Bernklev, T., Jahnsen, J., Henriksen, M., Lygren, I., Aadland, E., Sauar, J., et al. (2006). Relationship between sick leave, unemployment, disability, and health-related quality of life in patients with inflammatory bowel disease. Inflammatory Bowel Diseases, 12, 402-412.

Bjarnason, T., \& Sigurdardottir, T. J. (2003). Psychological distress during unemployment and beyond: social support and material deprivation among youth in six northern European countries. Social Science \& Medicine, 56(5), 973-985. 
Blaxter, M. (1990). Health and lifestyles. London: Routledge.

Claussen, B., Bjørndal, A., \& Hjort, P. F. (1993). Health and re-employment in a two year follow up of long term unemployed. Journal of Epidemiology and Community Health, 47, 14-18.

Czapiński, J., \& Panek, T. (2009). Social diagnose 2009, conditions and quality of life of poles. Annex 2. Warsaw: Social Monitoring Council, University of Finance and Management.

Eliason, M., \& Storrie, D. (2009). Job loss is bad for your health - Swedish evidence on cause - specific hospitalization following involuntary job loss. Social Science \& Medicine, 68(8), 1396-1406.

Geyer, S., \& Peter, R. (2003). Hospital admissions after transition into unemployment. Sozial und Präventivmedicin, 48, 105-114.

Glatzer, W. (2006). Quality of life in the European Union and the United States of America: evidence from comprehensive indices. Applied Research in Quality of Life, 1, 169-188.

Hintikka, J., Lehto, S. M., Niskanen, L., Huotari, A., Herzig, K.-H., Koivumaa-Honkanen, H., et al. (2009). Unemployment and ill health: a connection through inflammation ? BMC Public Health. doi:10.1186/ 1471-2458-9-410.

Holmes, T. H., \& Rahe, R. H. (1967). The social readjustment rating scale. Journal of Psychosomatic Research, 11(2), 213-218.

Jiang, Y., \& Hesser, J. E. (2006). Associations between health - related quality of live and demographics and health risks. Results from Rhode Islands 2002 behavioral risk factor survey. Health and Quality of Life Outcomes, 4, 1-9.

Jonge, J., \& Schaufeli, W. B. (1998). Job characteristics and employee well-being: a test of Warr's vitamin model in health care workers using structural equation modeling. Journal of Organizational Behavior, $19,387-407$.

Kalbarczyk, A. (1999). Psychological consequences of job loss and unemployment. In G. Kranas (Ed.), Organization, work, unemployment. Warsaw: W.U.W.

Kostrzewski, S., \& Worach-Kardas, H. (2008). Health, social and economic aspects of long-term unemployment in city environment. Problemy Higieny i Epidemiologii, 89(4), 500-506.

Kulczycka, L., Sysa-Jędrzejowska, A., \& Robak, E. (2007). Quality of life of patients with systemic lupus erythematosus and study methods. Progress in Hygiene and Experimental Medicine, 61, 473-477.

Latalski, M., Kulik, T. B., Ksykiewicz, D. A., Pacian, A., Skórzyńska, H., Żołnierczuk-Kieliszek, D., et al. (2004). Health problems in Lublin macroregion. Polish Journal of Public Health, 114(3), 174-177.

Leeflang, R. L. I., Klein-Hesselink, D. J., \& Spruit, I. P. (1992). Health effect of unemployment - I. Long term unemployed men in a rural and an urban setting. Social Science \& Medicine, 34(4), 341-350.

Linkola, P. (2007). New age policy in Finland since 1995. Warsaw: The Academy for the Development of Philanthropy in Poland.

Makowska, Z., \& Merecz, D. (2001). Evaluation of psychic life with the use of David Golberg questionnaire, manual for GHQ-12 and GHQ-28 questionnaires users. Łódź: Publishing Office of the J. Nofer Institute of Occupational Medicine.

Martella, D., \& Maass, A. (2000). Unemployment and life satisfaction: the moderating role of structure and collectivism. Journal of Applied Social Psychology, 30, 1095-1108.

Martikainen, P. T., \& Valkonen, T. (1996). Excess mortality of unemployed men and women during a period of rapidly increasing unemployment. The Lancet, 348, 909-913.

Mathers, C. D., \& Schofield, D. J. (1998). The health consequences of unemployment: the evidence. MJA, $168,178-182$.

McGregor, J. A., Camfield, L., \& Woodcock, A. (2009). Needs, wants and goals: wellbeing, quality of life and public policy. Applied research in Quality of Life, 4, 135-154.

Montgomery, S. M., Bartley, M. J., Cook, D. G., \& Wadsworth, M. E. (1996). Health and social precursors of unemployment in young men in Great Britain. Journal of Epidemiology and Community Health, 50, 415-422.

Novo, M., Hammarström, A., \& Janlert, U. (2001). Do high levels of unemployment influence the health of those who are not unemployed? A gendered comparison of young men and women during boom and recession. Social Science \& Medicine, 53(3), 293-303.

Nylén, L., Voss, M., \& Floderus, B. (2001). Mortality among women and men relative to unemployment, part time work, overtime work, and extra work: a study based on data from the Swedish twin registry. Occupational and Environmental Medicine, 58, 52-57.

Powdthavee, N. (2010). How much does money really matter? Estimating the causal effects of income on happiness. Empirical Economics, 39(1), 77-92.

Przewoźniak, L. (2000). Social and economic health conditions. In A. Czupryna, S. Poździoch, A. Ryś, \& W. C. Włodarczyk (Eds.), Public health journal (pp. 71-98). Kraków: University Medical Publishing House Vesalius. 
Rojas, M. (2011). Happiness, income, and beyond. Applied Research in Quality of Life, 6, 265-276.

Rowley, K. M., \& Feather, N. T. (1987). The impact of unemployment in relation to age and length of unemployment. Journal of Occupational Psychology, 60, 323-332.

Scanlan, J. N., \& Beltran, R. O. (2007). Work in unemployment - occupied or preoccupied? A review. Work: A Journal of Prevention, Assessment and Rehabilitation, 28(4), 325-334.

Straś-Romanowska, M., \& Frąckowiak, T. (2008). Stereotypes on ageing in the light of psychological studies. In J. T. Kowalski \& P. Szukalski (Eds.), Satisfying ageing in the view of humanities and social sciences. Łódź: Univesity of Lodz Publishing House.

The WHOQOL group. (1995). The World Health Organization quality of life assessment (WHOQOL): position paper from the World Health Organization. Social Science \& Medicine, 41(10), 1403-1409.

Urbaniak, B. (2007). Older employees on the labour market. In B. Urbaniak (Ed.), Employees aged 45 or older facing difficulties on the labour market. Warszawa: Elipsa Publishing House.

Vanassche, S., Swicegood, G., \& Matthijs, K. (2012). Marriage and children as a key to happiness? Crossnational differences in the effects of marital status and children on well-being. Journal of Happiness Studies. doi:10.1007/s10902-012-9340-8.

Veenhoven, R. (2008). Healthy happiness: effects of happiness on physical health and the consequences for preventive health care. Journal of Happiness Studies, 9(3), 449-469.

Warr, P. (2004). Psychological effects of long-term unemployment. In T. Chirkowska-Smolak \& A. Chudzicka (Eds.), An individual in the social perspective of unemployment. Poznań: Wydawnictwo Naukowe UAM.

Wciórka, B. (2007). A level of life satisfaction of poles in 1994-2006, a report from a study. Warsaw: Public Opinion Research Center.

Worach-Kardas, H. (1996). Unemployment and psychophysical health. Social Policy, 4, 25-30.

Zagożdżon, P., \& Ejsmond, J. (2008). Health-related quality of life in the unemployed. Problemy Higieny $i$ Epidemiologii, 89(4), 498-503.

Zahran, H. S., Moriarty, D. G., Zack, M. M., \& Kobau, R. (2003). Public health and aging: health-related quality of life among low-income persons aged 45-64 years United States, 1995-2001. Morbidity and Mortality Weekly Report, 52, 1120-1124. 